\title{
TLR9 polymorphisms in African populations: no association with severe malaria, but evidence of cis-variants acting on gene expression
}

\author{
Susana Campino*1,2, Julian Forton ${ }^{1}$, Sarah Auburn ${ }^{1,2}$, Andrew Fry ${ }^{1}$, \\ Mahamadou Diakite ${ }^{1}$, Anna Richardson ${ }^{1}$, Jeremy Hull ${ }^{3}$, Muminatou Jallow ${ }^{4}$, \\ Fatou Sisay-Joof ${ }^{4}$, Margaret Pinder ${ }^{4}$, Malcolm E Molyneux ${ }^{5}$, Terrie E Taylor ${ }^{6}$, \\ Kirk Rockett ${ }^{1}$, Taane G Clark ${ }^{1,2}$ and Dominic P Kwiatkowski ${ }^{1,2}$
}

\begin{abstract}
Address: ${ }^{1}$ Wellcome Trust Centre for Human Genetics, University of Oxford, Roosevelt Drive, Oxford, OX3 7BN, UK, 2 Wellcome Trust Sanger Institute, Hinxton, Cambridge, CB10 1SA, UK, ${ }^{3}$ University Department of Paediatrics, John Radcliffe Hospital, Oxford, OX3 9DU, UK, ${ }^{4}$ Medical Research Council Laboratories, Atlantic Boulevard, Fajara, PO Box 273, Banjul, the Gambia, ${ }^{5}$ Malawi-Liverpool-Wellcome Programme of Clinical Tropical Research, College of Medicine, Blantyre, PO Box 30096, Malawi and ${ }^{6}$ Blantyre Malaria Project, College of Medicine, Blantyre, PO Box 30096, Malawi

Email: Susana Campino* - sc11@sanger.ac.uk; Julian Forton - Julian.Forton@paediatrics.ox.ac.uk; Sarah Auburn - sa3@sanger.ac.uk; Andrew Fry - afry@well.ox.ac.uk; Mahamadou Diakite - m.diakite@well.ox.ac.uk; Anna Richardson - anna.richardson@well.ox.ac.uk; Jeremy Hull - Jeremy.hull@paediatrics.ox.ac.uk; Muminatou Jallow - muminatou@yahoo.com; Fatou Sisay-Joof - fjoof@hotmail.com; Margaret Pinder - mpinder@mrc.gm; Malcolm E Molyneux - mmolyneux@malawi.net; Terrie E Taylor - taylort@msu.edu; Kirk Rockett - Kirk.Rockett@well.ox.ac.uk; Taane G Clark -tc5@sanger.ac.uk; Dominic P Kwiatkowski - Dominic@well.ox.ac.uk

* Corresponding author
\end{abstract}

Published: 13 March 2009

Malaria Journal 2009, 8:44 doi:10.1 I86/1475-2875-8-44

This article is available from: http://www.malariajournal.com/content/8/I/44

(c) 2009 Campino et al; licensee BioMed Central Ltd.

This is an Open Access article distributed under the terms of the Creative Commons Attribution License (http://creativecommons.org/licenses/by/2.0), which permits unrestricted use, distribution, and reproduction in any medium, provided the original work is properly cited.
Received: 14 August 2008 Accepted: 13 March 2009

\begin{abstract}
Background: During malaria infection the Toll-like receptor 9 (TLR9) is activated through induction with plasmodium DNA or another malaria motif not yet identified. Although TLR9 activation by malaria parasites is well reported, the implication to the susceptibility to severe malaria is not clear. The aim of this study was to assess the contribution of genetic variation at TLR9 to severe malaria.
\end{abstract}

Methods: This study explores the contribution of TLR9 genetic variants to severe malaria using two approaches. First, an association study of four common single nucleotide polymorphisms was performed on both family- and population-based studies from Malawian and Gambian populations ( $n>6000$ individual). Subsequently, it was assessed whether TLR9 expression is affected by cis-acting variants and if these variants could be mapped. For this work, an allele specific expression (ASE) assay on a panel of HapMap cell lines was carried out.

Results: No convincing association was found with polymorphisms in TLR9 for malaria severity, in either Gambian or Malawian populations, using both case-control and family based study designs. Using an allele specific expression assay it was observed that TLR9 expression is affected by cisacting variants, these results were replicated in a second experiment using biological replicates.

Conclusion: By using the largest cohorts analysed to date, as well as a standardized phenotype definition and study design, no association of TLR9 genetic variants with severe malaria was found. This analysis considered all common variants in the region, but it is remains possible that there are 
rare variants with association signals. This report also shows that TLR9 expression is potentially modulated through cis-regulatory variants, which may lead to differential inflammatory responses to infection between individuals.

\section{Background}

Exploring the idea that malaria motifs can induce the innate immune system and initiate an inflammatory response may lead to a greater understanding of resistance/susceptibility to severe malaria. Several reports have found that malaria parasites express molecules that are recognized by Toll-like receptors (TLR), which play a critical role in the early innate immune response to invading pathogens. For instance, the malaria pigment haemozoin has been shown to function as carrier for plasmodium DNA which stimulates TLR9 and induces inflammation [1-3]. Activation of TLR9 expressed on dendritic cell has also been proposed as a mechanism used by malaria parasites to trigger regulatory $\mathrm{T}$ cells and evade the immune system [4]. Regulatory T cells were also shown to contribute to the pathogenesis of severe malaria by suppressing anti-malarial immunity during Plasmodium berghei ANKA infection [5]. The correct balance between induction of an immune response against the malaria parasite and limitation of suppression of host immunity by the parasite seems essential to control infection.

To assess the clinical relevance of TLR9 polymorphisms and severe malaria two association studies were conducted in Ghana. While one of the studies did not observe any clear association with severe malaria[6], another found TLR9 polymorphisms to be associated with the clinical manifestation of malaria during pregnancy [7]. Recently, the TLR-9-1486C/T variants was found to be associated with high parasitaemia in a cohort of patients with mild malaria from the Amazonian region of Brazil [8].

This report explores the contribution of TLR9 genetic variants to severe malaria using two approaches. At first, a large case-control and family-based association studies was performed in Malawian and Gambian populations using four common polymorphisms located in the TLR9 gene region. It is also known that distant SNPs can affect gene expression, and these can only be identified using functional in vitro assays [9-11]. Therefore, subsequently it was assessed whether TLR9 expression is affected by cisacting variants and whether these variants could be mapped. Such polymorphism can be further investigated as candidates for possible association with severe malaria. Exploiting the fact that TLR9 is a major TLR expressed by human B cells [12], an allele specific expression (ASE) assay was performed using HapMap [13] B-lymphoblastoid cell lines (LCLs), for which genotypes on hundreds-of- thousands SNPs exist, permitting the correlation between expression data and genetic variability [11,14-17] and thus facilitating the discovery of putative functional polymorphisms.

\section{Methods \\ Study participants}

Patient samples were collected as part of ongoing epidemiological studies of severe malaria at the Royal Victoria Hospital, Banjul, The Gambia (885 severe malaria cases, 629 controls; 1,044 family trios) and the Queen Elizabeth Central Hospital, Blantyre, Malawi (712 severe malaria cases, 416 controls; 248 family trios). The set of nuclear family trios comprise a severe malaria affected child and its two (biological) parents, and were assessed as 'true trios' using the Nuclear software package[18]. All DNA samples were collected and genotyped following approval from the relevant research ethics committees and informed consent from participants.

\section{Phenotypic definition}

All cases were children admitted to hospital with evidence of Plasmodium falciparum on blood film and clinical features of severe malaria [19]. Subjects were defined as having had 'cerebral malaria' if their Blantyre coma score was less than or equal to 3 on presentation or early during admission. A second phenotypic subset of 'severe malarial anaemia' was defined as those subjects having had a haemoglobin density of less than $5 \mathrm{~g} / \mathrm{dl}$ or a haematocrit less than $15 \%$. Participants with co-existing severe or chronic medical conditions (e.g. bacterial pneumonia, kwashiorkor) unrelated to a severe malarial infection were excluded. Controls were cord blood samples obtained from birth clinics in the same locality as the cases, and thought to approximate a random sample of the population thus, reflecting the true allele frequency. Cerebral malaria (CM) and severe malarial anaemia (SMA) were the most common symptoms defining severe malaria.

\section{Sample preparation and genotyping}

For the association studies (participants described below) genomic DNA samples underwent whole genome amplification through either Primer Extension Pre-amplification [20] or Multiple Displacement Amplification [21], before genotyping on a Sequenom MassArray genotyping platform. Only the four common SNPs (minor allele frequency (MAF) of at least 5\% in the HapMap Yoruba population) in the TLR9 region were genotyped. The majority of polymorphisms in this region are monomorphic. 
For the ASE assay 19 unrelated CEU and 20 YRI individuals were used, selected from the HapMap collection. Established lymphoblastoid cell lines (LCLs) from these individuals were obtained from the Centre d'Etude du Polymorphisme Humain (CEPH) collection (Coriell Institute for Medical Research). Cell lines were cultured has described previously [22].

\section{Expression phenotyping}

For expression analysis, total RNA was extracted from cells lines from each individual using Tri reagent (Sigma). Poly A+ RNA was isolated from total RNA using the Dynabeads mRNA Purification Kit (Dynal). Synthesis of First-Strand cDNA was processed according to the StrataScript ${ }^{\mathrm{TM}}$ FirstStrand Synthesis System (Stratagene). The Allelotype platform from Massarray (Sequenom) was utilized for accurate relative quantification of allele specific cDNA and gDNA transcripts [23]. Primers were designed using the dedicated software Spectrodesigner (Sequenom). Allele specific expression quantification was performed according to the protocol of Forton et al [15] and Campino et al [24]. Briefly, for each cDNA and gDNA assays, nine technical replicates were performed. Biological replicates from independent cultures were assayed equally. For a given cDNA or gDNA assay the allelic transcript ratio was calculated on each of the nine technical replicates from the relative quantity of the two allele-specific transcripts. The mean allelic transcript ratio for the whole assay was then calculated, and normalized to the mean allelic transcript ratio for the genomic controls. An assay was accepted for further analysis if the standard error of the mean for the technical and biological replicates was less than 10\%.

\section{HAPMAP haplotypes}

Haplotypes were downloaded from the HapMap Phase II database http://www.hapmap.org. For data analysis, 770,394 markers were used; all monomorphic markers were excluded from the analysis. Locations of the SNP markers were based on those of the human reference sequence http://genome.ucsc.edu of May 2004 (hg 17, build 35).

\section{Statistical analysis of the case-control and family trio association studies}

Genotypic deviations from Hardy-Weinberg equilibrium (HWE) were assessed using a chi-square statistical test. Case-control association analysis was undertaken by logistic regression and included the covariates: ethnic group, gender and the HbS polymorphism. Family-based association analysis was performed using the transmission disequilibrium test (TDT) [25], as well as a casepseudo-control approach with conditional logistic regression [26]. The TDT test is robust to the effects of population stratification or sub-structure. All analysis was performed using the R statistical package.

\section{Statistical analysis of allelic expression}

For the association analysis, log-transformed ratios of allele expression values for individuals with the heterozygous genotype at the exonic SNP (rs352140) were used. To map putative cis-variants a statistical analysis approach was used, based on the linear regression method (similar to that developed by Teare et al and Campino et al)[24,27]. In particular, it was assessed whether there is evidence of an increasing or decreasing (linear) relationship between the ratio of expressions for the phase-known heterozygous type 1 (e.g. AG), homozygous types (e.g. AA and GG), and heterozygous type 2 (e.g. GA) genotypes. The rationale for the approach is that allelic imbalances would be observed only in individuals heterozygous for the cis-acting polymorphism. All analysis was performed using the R statistical package.

\section{Results and discussion \\ Association analyses of common TLR9 SNPs and severe malaria}

To assess the contribution TLR9 polymorphisms to severe malaria susceptibility/resistance an association analysis was performed using case-control and trio cohorts from Malawian (712 cases, 416 controls; 248 family trios) and The Gambian (885 cases, 629 controls; 1,044 family trios). Cerebral malaria and severe anaemia were the most common symptoms defining severe malaria. The majority of the Gambian (70\%) and Malawian (91\%) cohorts comprise cases of cerebral malaria.

Of the four common SNPs in the TLR9 region genotyped in the Malawian and Gambian cohorts, two were located in the promoter $(-1486 \mathrm{~T}>\mathrm{C}$ rs187084, $-1237 \mathrm{C}>\mathrm{T}$ rs5743836), one was intronic (+1174 A>G rs352139) and the last was a synonymous SNP located on exon $2(+2848$ $\mathrm{G}>\mathrm{A}$ rs352140). The observed MAFs observed in the cohorts are presented in Table 1 . There is no evidence of distortion from Hardy-Weinberg equilibrium (HWE) in the controls or parents $(\mathrm{P}>0.05)$. There is a high degree of concordance of the allele frequencies within country and between the two study designs. The intronic SNP $(+1174-\mathrm{X})$ is in high linkage disequilibrium (LD) with the other SNPs, especially with the exonic SNP (+2848-X) with which it shows a near complete LD $\left(D^{\prime}=0.95\right.$ in the Malawian cohort and 0.99 in the Gambian) (Figure 1).

The allele frequencies between the Gambian cases and controls and among the parents and children from the trios are very similar (odds ratios (OR) close to 1 in both studies) (see Table 2). In the Malawian case-control cohort we observed a weak association between allele 1174-A and severe malaria (OR $=1.21,95 \%$ CI $1.01-$ $1.45 ; \mathrm{p}=0.04)$. The allele 2848 - $\mathrm{T}$ showed a marginal protective effect $(\mathrm{OR}=0.82,95 \%$ CI $0.68-1.00 ; \mathrm{p}=0.05)$. The +1174 and +2848 SNPs are in near perfect LD (D' 


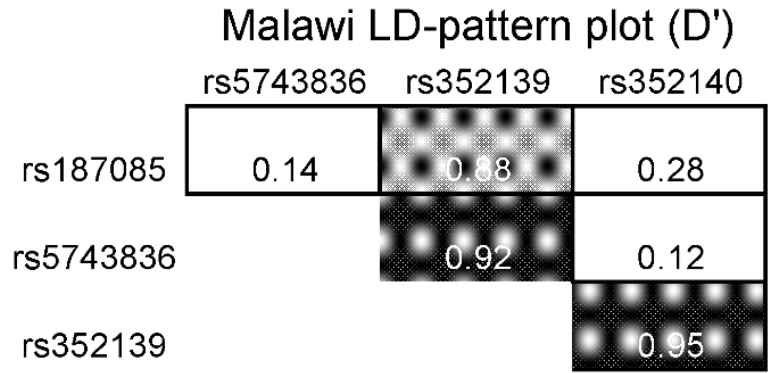

Malawi LD-pattern plot (D') rs5743836 rs352139 rs352140

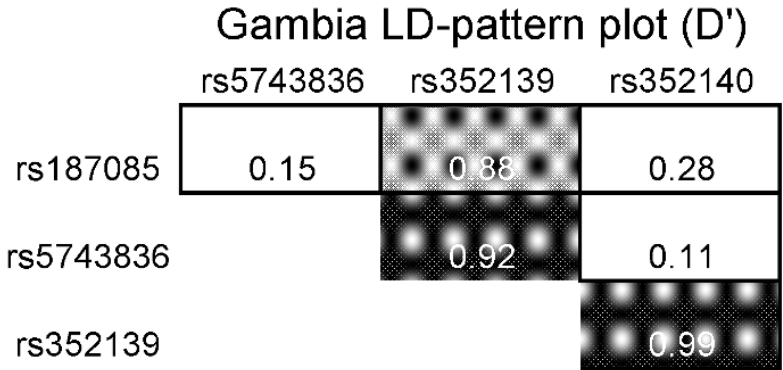

\section{Figure I}

Linkage disequilibrium patterns between TLR9 polymorphisms in Malawian and Gambian cohorts. Pairwise linkage disequilibrium between the four TLR9 polymorphisms was calculated using the normalized disequilibrium coefficient (D').

close to one) and only three possible haplotypes exist (1174-A/2848-C, 1174-G/2848-C, 1174-G/2848-T). The relative risk of disease (95\% CI) for haplotypes 1174-G/ 2848-C, 1174-G/2848-T and 1174-A/2848-C are 0.95 (95\% CI: $1.01-1.33$ ), 0.86 (95\% CI $0.80-1.11)$ and 1.15 (95\% CI: $0.73-1.03$ ) with p-values of $0.05,0.45$ and 0.10 respectively. However the effect of these polymorphisms was not reproducible in the trios, where allele frequencies between parents and children were comparable, and there was no evidence of transmission distortion and association (Table 2). In the case-control analyses, the allelic tests do not adjust for any confounding effects, such as population substructure, that can affect bias estimates in casecontrol study designs. In the genotype analysis of the casecontrols (Table 3), adjusted for the HbS sickle cell polymorphism, and also ethnicity in the Gambian study, no strong signals of genotypic association was found for any of the four polymorphisms.

The analysis of the Gambia case-control cohorts showed that there was no evidence of association between severe malaria and the polymorphisms studied. Similarly for the
Malawi case-controls, there was no strong evidence of association, but there are some marginal effects consistent with the haplotype and allelic analyses above. Accounting for multiple testing would make us less likely to believe the marginal evidence $(P \approx 0.05)$ of associations for some of the polymorphisms and potential haplotype effects. Mantel-Haenszel pooled estimates of risk for each SNP across the populations and studies did not lead to significant results ( $p>0.05)$. In conclusion, no convincing association was found with polymorphisms at TLR9 for malaria severity, in either Gambian or Malawian populations, using both case-control and family based study designs

\section{Exploring the existence of functional polymorphism affecting TLR9 allelic expression}

Candidate gene genetic studies are generally restricted to SNPs covering the gene area as potential regulatory SNPs localized away from a gene are difficult to identify. Therefore, as no association was found with SNPs in the TLR9 gene area, there was further exploration into whether other SNPs which can be far away from the gene could

Table I: Allelic frequencies of TLR9 polymorphisms

\begin{tabular}{|c|c|c|c|c|c|}
\hline & & \multicolumn{2}{|c|}{ Gambia } & \multicolumn{2}{|c|}{ Malawi } \\
\hline & & Controls 1 & Cases & Controls 1 & Cases \\
\hline Case-control (n) & allele & 628 & 883 & 416 & $7 / 2$ \\
\hline TLR9_rs 187084 & $\mathrm{C}$ & 0.231 & 0.227 & 0.270 & 0.232 \\
\hline TLR9_rs5743836 & $\mathrm{C}$ & 0.460 & 0.438 & 0.407 & 0.381 \\
\hline TLR9_rs352139 & A & 0.395 & 0.413 & 0.396 & 0.444 \\
\hline TLR9_rs352140_exonic & $\mathrm{T}$ & 0.244 & 0.249 & 0.302 & 0.263 \\
\hline $\operatorname{Trios}(n)$ & & 2086 & 1043 & 376 & 188 \\
\hline TLR9_rs187084 & C & 0.237 & 0.236 & 0.269 & 0.266 \\
\hline TLR9_rs5743836 & $\mathrm{C}$ & 0.481 & 0.478 & 0.406 & 0.399 \\
\hline TLR9_rs352139 & A & 0.435 & 0.418 & 0.378 & 0.391 \\
\hline TLR9_rs352140_exonic & $\mathrm{T}$ & 0.248 & 0.249 & 0.323 & 0.321 \\
\hline
\end{tabular}

I For the trios' cohort the parents were used as controls. 
Table 2: Severe malaria and TLR9 allelic-based association analysis

\begin{tabular}{|c|c|c|c|c|c|c|c|c|c|}
\hline \multirow{3}{*}{$\begin{array}{l}\text { Case-control } \\
\text { rs/87084 }\end{array}$} & \multirow{3}{*}{$\begin{array}{l}\text { alleles } \\
\text { C vs T }\end{array}$} & \multicolumn{4}{|c|}{ The Gambia } & \multicolumn{4}{|c|}{ Malawi } \\
\hline & & \multirow{2}{*}{$\begin{array}{l}\mathrm{OR}^{\prime} \\
0.98\end{array}$} & \multicolumn{2}{|c|}{$95 \% \mathrm{Cl}^{2}$} & \multirow{2}{*}{$\begin{array}{c}\text { p-value }{ }^{3} \\
0.81\end{array}$} & \multirow{2}{*}{$\begin{array}{l}\text { OR } \\
0.82\end{array}$} & \multicolumn{2}{|c|}{$95 \% \mathrm{Cl}$} & \multirow{2}{*}{$\frac{P \text {-value }}{3}$} \\
\hline & & & 0.82 & 1.16 & & & 0.66 & 1.01 & \\
\hline rs5743836 & C vs T & 0.92 & 0.78 & 1.07 & 0.26 & 0.90 & 0.75 & 1.08 & 0.26 \\
\hline rs352139 & $A$ vs $G$ & 1.08 & 0.93 & 1.25 & 0.33 & 1.21 & 1.01 & 1.45 & 0.04 \\
\hline rs352140 & T vs $C$ & 1.03 & 0.87 & 1.21 & 0.77 & 0.82 & 0.68 & 1.00 & 0.05 \\
\hline \multicolumn{10}{|l|}{ Trios } \\
\hline rs|87084 & $C$ vs $\mathrm{T}$ & 0.95 & 0.82 & I.II & 0.55 & 0.91 & 0.66 & 1.26 & 0.56 \\
\hline rs5743836 & C vs T & 0.95 & 0.78 & 1.16 & 0.62 & 0.82 & 0.59 & 1.16 & 0.26 \\
\hline rs352139 & $A$ vs $G$ & 0.92 & 0.82 & 1.05 & 0.22 & 1.07 & 0.77 & 1.49 & 0.67 \\
\hline rs352140 & T vs $C$ & 1.00 & 0.87 & 1.16 & 0.97 & 0.99 & 0.72 & 1.36 & 0.94 \\
\hline
\end{tabular}

$\mathrm{IOR}=$ odds ratio,

$2 \mathrm{Cl}=$ confidence interval

3 for the trios these are TDT p-values

have an important role on the regulation of TLR9 expression.

Numerous studies have recently contributed to the identification of putative regulatory variants by correlating total gene expression or allele specific expression data with genetic variability $[11,16,17,28]$ Using a similar approach, in this report an allele specific expression (ASE) assay was performed on a panel of HapMap B-lymphoblastoid cell lines (LCL) for which genotyped data is available and facilitates the mapping of functional polymorphisms. These cell lines have been widely used to map cis/trans regulatory regions and recent publications have shown high consistence between cis-regulation results obtained using HapMap cell lines and primary tissue[29].

The strength of the ASE assay is the possibility to compare the relative expression of the two alleles in heterozygous individuals within the same cellular sample. Therefore, both alleles will be exposed to the same environmental, technical and genetic factors (e.g. trans-acting effect). If the expression of the alleles is not equal (allelic imbalance), it suggests that the expression of the gene is under cis-regulation.

Cell lines from individuals of northern and western Europe origin (CEU) and from Yoruba of Ibadan, Nigeria (YRI) were selected from the HapMap collection [13] and were genotyped for a exonic synonymous SNP present on the TLR9 gene. Since this SNP is located within a part of the gene that is transcribed, it is possible to discriminate between allelic transcripts in heterozygous individuals.

Twenty-one unrelated CEU and nineteen YRI individuals were found to be heterozygous for this SNP and were used for the ASE analysis. For these individuals, their genomic DNA was used to obtain the reference equi-molar ratio between the two alleles (allele1 and allele2), and this was

Table 3: Severe malaria and TLR9 genotype-based association analysis

\begin{tabular}{|c|c|c|c|c|c|c|c|c|c|}
\hline \multirow{3}{*}{$\begin{array}{l}\text { Case-control } \\
\text { rs|87084 }\end{array}$} & \multirow{3}{*}{$\begin{array}{l}\text { genotypes } \\
\text { CT vs TT }\end{array}$} & \multicolumn{4}{|c|}{ The Gambia' } & \multicolumn{4}{|c|}{ Malawi $^{2}$} \\
\hline & & \multirow{2}{*}{$\begin{array}{c}\text { OR } \\
0.96\end{array}$} & \multicolumn{2}{|c|}{$95 \% \mathrm{Cl}$} & \multirow{2}{*}{$\begin{array}{c}\text { P-value } \\
0.79\end{array}$} & \multirow{2}{*}{$\begin{array}{c}\text { OR } \\
0.82\end{array}$} & \multicolumn{2}{|c|}{$95 \% \mathrm{Cl}$} & \multirow{2}{*}{$\begin{array}{c}\text { P-value } \\
0.17\end{array}$} \\
\hline & & & 0.75 & 1.23 & & & 0.62 & 1.09 & \\
\hline & $\mathrm{CC} v \mathrm{TT}$ & 0.98 & 0.57 & 1.70 & 0.97 & 0.60 & 0.35 & 1.02 & 0.06 \\
\hline \multirow[t]{2}{*}{ rs5743836 } & CT vs TT & 0.98 & 0.74 & 1.30 & 0.90 & 1.01 & 0.75 & 1.34 & 0.95 \\
\hline & CC vs TT & 0.81 & 0.56 & 1.15 & 0.25 & 0.63 & 0.42 & 0.97 & 0.04 \\
\hline \multirow[t]{2}{*}{ rs352139 } & $A G$ vs $G G$ & 1.01 & 0.77 & 1.30 & 0.97 & 1.22 & 0.91 & 1.63 & 0.17 \\
\hline & $A A$ vs $G G$ & 1.22 & 0.85 & 1.74 & 0.27 & 1.43 & 0.98 & 2.07 & 0.06 \\
\hline \multirow[t]{2}{*}{ rs352140 } & TC vs CC & 0.97 & 0.76 & 1.24 & 0.84 & 0.77 & 0.59 & 1.01 & 0.06 \\
\hline & TT vs CC & 1.36 & 0.82 & 2.26 & 0.22 & 0.78 & 0.49 & 1.25 & 0.31 \\
\hline
\end{tabular}

IAdjusted for $\mathrm{HbS}$ and ethnicity

${ }^{2}$ Adjusted for $\mathrm{HbS}$ 
then compared with their allelic RNA expression. Allelic expression imbalance (AEI) was determined if independent replicate assays in the RNA samples showed differential allele expression ratios that deviated from the genomic DNA. If there is no allelic imbalance then the ratio of the two alleles (allele1/allele2) will be equal to one. A ratio greater than one indicates an over-expression of allele1, while a ratio smaller than one indicates an overexpression of allele2.

Of the 21 CEU individuals, 17 (84\%) showed no or low magnitude allelic variation (both alleles expressed nearly equally) (Figure 2). However, for three individuals, the allelic transcript A was clearly over-expressed (ratios between 1.3 and 1.87) and for one individual this allelic transcript was clearly under-expressed (average ratio of $0.5)$. As for the CEU population, almost all the YRI samples $(80 \%)$ showed low magnitude allelic variation (Figure 2). However, three individuals showed overexpression (ratios between 1.2 and 1.67) of allele A, and one individual relatively under-expression of the same allele (average ratio of 0.7). Biological replicates from independent cultures yielded convergent results (Pearson correlation coefficient $r=0.84$ ). Since the overall experimental variability was very low, being little influenced by variations in cell culture or other experimental tech-

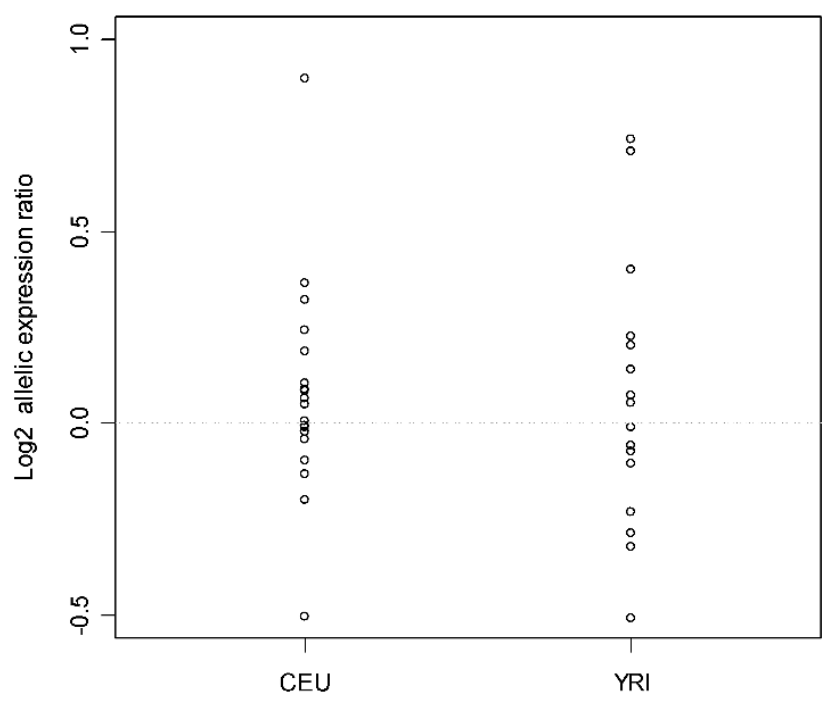

Figure 2

Allele specific differences in TLR9 expression. Log2 allelic expression ratio between the $A$ allele and the $G$ allele in individuals heterozygous for the rs352140. Represented are the results for the $21 \mathrm{CEU}$ and $19 \mathrm{YRI}$ individuals. The mean allelic transcript ratio for each cDNA sample was normalised to the mean allelic transcript ratio of the respective gDNA control. The horizontal dashed lines indicate the $A / G$ allele ratio of $\mathrm{I}$. niques, these results strongly suggest that the allelic imbalances observed in the six individuals studied here represent a true biological phenomenon. As the allelic imbalance data observed was bidirectional, i.e. showing over-expression of different alleles among the cell lines, the cis-acting variant is likely to be in low LD with the transcript SNP $[15,27]$.

To map potential cis-acting variants that might be responsible for the allelic imbalances observed in the TLR9 gene, the allele ratio data is correlated with haplotypes ( $\sim 400 \mathrm{~kb}$ surrounding each side of the TLR9 gene) of the HapMap individuals considered using a linear regression approach (described in materials and methods) $[15,24]$. CEU and YRI sample sets were analysed independently. No significant associations were found between allelic imbalances and the 278 SNPs surrounding TLR9 gene including the promoter and intronic SNPs analysed (Figure 3). The fact that it was not possible to map any putative cis-variants might be because the allelic imbalances observed were caused by variants still not represented by HapMap data at the current level of SNP ascertainment or due to the reduced statistical power resulting from the small sample size used (21 CEU and 19 YRI).

Overall, while no functional polymorphism were mapped using the current HapMap genotyping data, this data shows that TLR9 expression is potentially modulated through cis-regulatory variants.

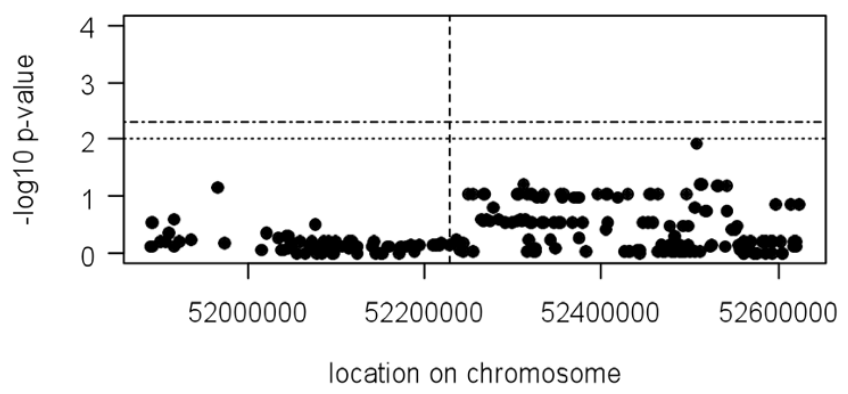

Figure 3

Mapping putative cis-variants acting on TLR9 gene expression. Allele transcript ratio mapping for 278 SNP across $\sim 400 \mathrm{~kb}$ each side of the TLR9 gene. No association was found with any SNP surrounding the TLR9 gene. Y-axis represents the $-\log _{10} \mathrm{P}$-value and the $\mathrm{X}$-axis the location in the chromosome. The horizontal dashed line indicates a nominal $\mathrm{p}$-value of $0.0 \mathrm{l}$. The horizontal dashed and pointed line indicates the region-wide significance threshold of $1 \%$ calculated by performing 1000 permutations. The vertical dashed line indicates the position of the TLR9 transcribed SNP (rs352 I40). Each bullet represents a tested SNP. This data was obtained using the CEU data set. Similar results were obtained for the YRI. 


\section{Conclusion}

To determine if genetic variation in the TLR9 gene influences disease outcome in malaria, a genetic association study was conducted to investigate the possible effect of TLR9 polymorphisms on severe malaria in two African populations. This study uses a standardized phenotype definition and study design, is the largest of its kind to date for TLR9, and includes both case-control and familybased data. No association was found with TLR9 polymorphism and severe manifestation of malaria in the Gambian cohorts and only a weak effect was observed in the Malawi case-control study. In the latter, it was not possible to adjust the potentially confounding effect of ethnicity, and possible population structure. When the more robust TDT analysis was applied to the Malawian trios, no association was observed. This analysis considered all common variants in the TLR9 region, but it remains possible that there are rare variants with association signals.

It is also possible that there exist TLR9 regulatory variants that contribute to severe malaria resistance/susceptibility that have not been mapped. It is known that regulatory polymorphisms which control gene expression can be localized hundreds of $\mathrm{kb}$ from the gene they influence[10,15]. Selection of candidate SNPs for association analysis close to the gene of interest is therefore likely to miss distant functional polymorphisms. One approach that will enrich potential functional polymorphism in association analysis is to use expression studies to identify SNPs that modulate gene expression. In an attempt to find putative cis-variants affecting TLR9 expression, an allelespecific expression assays was carried out in LCL from both CEU and YRI HapMap individuals. Interestingly, allelic expression imbalances were observed in both sample sets, which is reproducible in the same individuals, indicating strongly the existence of cis-regulation. This observation indicates clearly that different individuals might differ in the expression of TLR9, which can lead to different responses to the stimulus induced by malaria motifs or other pathogens. The identification of these functional genetic variants will be crucial to attest any involvement of TLR9 in severe malaria. The finding that TLR9 expression is under cis-regulation will strongly pave the path for further studies of infectious diseases, including the consequences of differential TLR9 activation.

Although evidence of cis-regulation of TLR9 expression was found, it was not possible to identify polymorphisms that correlated with the observed distortion. This is likely to be due to the incomplete polymorphism coverage of the HapMap and by the small sample sizes of the current available LCL. Increasing the number of available cell lines with abundant genotyping data or the application of new re-sequencing technologies to discover new and rare polymorphism will greatly facilitate the identification of functional variants. This work illustrates the need to upscale approaches and resources in expression analysis in the search for disease associated variants.

\section{Competing interests}

The authors declare that they have no competing interests.

\section{Authors' contributions}

SC coordinated the project, carried out the molecular genetic studies, statistical analysis and wrote the manuscript. JF, SA, AR, AF, JH, MD helped in the molecular genetic studies and writing the manuscript. TC performed the statistical analysis and helped writing the paper. MJ, FS, MP, MM, TT coordinated sample collection and DNA extraction. SC, KR, DK conceived the study, and participated in its design and coordination and helped to draft the manuscript.

\section{Acknowledgements}

This work was in part funded by the Wellcome Trust and Medical Research Council UK. SC was funded by a Marie-Curie intra-European fellowship (FP6). JF and AF were funded by a Wellcome Trust Training Fellowship. TGC, SA, KR and DPK are in part funded by the Bill and Melinda Gates Foundation, Wellcome Trust, and Medical Research Council UK.

\section{References}

I. Coban C, Ishii KJ, Kawai T, Hemmi H, Sato S, Uematsu S, Yamamoto M, Takeuchi O, Itagaki S, Kumar N, Horii T, Akira S: Toll-like receptor 9 mediates innate immune activation by the malaria pigment hemozoin. J Exp Med 2005, 20 I: 19-25.

2. Pichyangkul S, Yongvanitchit K, Kum-arb U, Hemmi H, Akira S, Krieg AM, Heppner DG, Stewart VA, Hasegawa H, Looareesuwan S, Shanks GD, Miller RS: Malaria blood stage parasites activate human plasmacytoid dendritic cells and murine dendritic cells through a Toll-like receptor 9-dependent pathway. J Immunol 2004, 172:4926-4933.

3. Parroche P, Lauw FN, Goutagny N, Latz E, Monks BG, Visintin A, Halmen KA, Lamphier M, Olivier M, Bartholomeu DC, Gazzinelli RT, Golenbock DT: Malaria hemozoin is immunologically inert but radically enhances innate responses by presenting malaria DNA to Toll-like receptor 9. Proc Natl Acad Sci USA 2007, 104:1919-1924.

4. Hisaeda H, Tetsutani K, Imai T, Moriya C, Tu L, Hamano S, Duan X, Chou B, Ishida $\mathrm{H}$, Aramaki A, Shen J, Ishii KJ, Coban C, Akira S, Takeda K, Yasutomo K, Torii M, Himeno K: Malaria Parasites Require TLR9 Signaling for Immune Evasion by Activating Regulatory T Cells. J Immunol 2008, 180:2496-2503.

5. Amante FH, Stanley AC, Randall LM, Zhou Y, Haque A, McSweeney K, Waters AP, Janse CJ, Good MF, Hill GR, Engwerda CR: A role for natural regulatory $T$ cells in the pathogenesis of experimental cerebral malaria. Am J Pathol 2007, I 7 I:548-559.

6. Mockenhaupt FP, Cramer JP, Hamann L, Stegemann MS, Eckert J, Oh NR, Otchwemah RN, Dietz E, Ehrhardt S, Schroder NW, Bienzle U, Schumann RR: Toll-like receptor (TLR) polymorphisms in African children: common TLR-4 variants predispose to severe malaria. J Commun Dis 2006, 38:230-245.

7. Mockenhaupt FP, Hamann L, von Gaertner C, Bedu-Addo G, von Kleinsorgen $C$, Schumann RR, Bienzle U: Common polymorphisms of toll-like receptors 4 and 9 are associated with the clinical manifestation of malaria during pregnancy. J Infect Dis 2006, 194:184-188.

8. Leoratti FM, Farias L, Alves FP, Suarez-Mutis MC, Coura JR, Kalil J, Camargo EP, Moraes SL, Ramasawmy R: Variants in the Toll-Like Receptor Signaling Pathway and Clinical Outcomes of Malaria. J Infect Dis 2008.

9. Pastinen T, Hudson TJ: Cis-acting regulatory variation in the human genome. Science 2004, 306:647-650. 
10. Stranger BE, Nica AC, Forrest MS, Dimas A, Bird CP, Beazley C, Ingle $\mathrm{CE}$, Dunning M, Flicek P, Koller D, Montgomery S, Tavare S, Deloukas $P$, Dermitzakis ET: Population genomics of human gene expression. Nat Genet 2007, 39: I2 17-I224.

II. Cheung VG, Spielman RS, Ewens KG, Weber TM, Morley M, Burdick $\mathrm{JT}$ : Mapping determinants of human gene expression by regional and genome-wide association. Nature 2005, 437:1365-1369.

12. Bernasconi NL, Onai N, Lanzavecchia A: A role for Toll-like receptors in acquired immunity: up-regulation of TLR9 by BCR triggering in naive $B$ cells and constitutive expression in memory B cells. Blood 2003, 10 I:4500-4504.

13. The International HapMap Project. Nature 2003, 426:789-796.

14. Hull J, Campino S, Rowlands K, Chan MS, Copley RR, Taylor MS, Rockett K, Elvidge G, Keating B, Knight J, Kwiatkowski D: Identification of common genetic variation that modulates alternative splicing. PLoS Genet 2007, 3:e99.

15. Forton JT, Udalova IA, Campino S, Rockett KA, Hull J, Kwiatkowski DP: Localization of a long-range cis-regulatory element of ILI 3 by allelic transcript ratio mapping. Genome Res 2007, 17:82-87.

16. Stranger BE, Forrest MS, Clark AG, Minichiello MJ, Deutsch S, Lyle R, Hunt S, Kahl B, Antonarakis SE, Tavare S, Deloukas P, Dermitzakis ET: Genome-wide associations of gene expression variation in humans. PLoS Genet 2005, I:e78.

17. Pastinen T, Ge B, Gurd S, Gaudin T, Dore C, Lemire M, Lepage P, Harmsen E, Hudson TJ: Mapping common regulatory variants to human haplotypes. Hum Mol Genet 2005, I 4:3963-397I.

18. Teo YYFA, Sanjoaquin MA, Pederson B, Small KS, Rockett KA, Kwiatkowski DP, Clark TG: Assessing genuine parents-offspring trios for genetic association studies. Hum Heredity 2008.

19. Marsh K, Forster D, Waruiru C, Mwangi I, Winstanley M, Marsh V, Newton C, Winstanley P, Warn P, Peshu N, et al.: Indicators of lifethreatening malaria in African children. N Engl ] Med 1995, 332:1399-1404.

20. Zhang L, Cui X, Schmitt K, Hubert R, Navidi W, Arnheim N: Whole genome amplification from a single cell: implications for genetic analysis. Proc Natl Acad Sci USA 1992, 89:5847-585I.

21. Gonzalez JM, Portillo MC, Saiz-Jimenez C: Multiple displacement amplification as a pre-polymerase chain reaction (pre-PCR) to process difficult to amplify samples and low copy number sequences from natural environments. Environ Microbiol 2005, 7:1024-1028.

22. Knight JC, Keating BJ, Kwiatkowski DP: Allele-specific repression of lymphotoxin-alpha by activated B cell factor-I. Nat Genet 2004, 36:394-399.

23. Elvidge GP, Price TS, Glenny L, Ragoussis J: Development and evaluation of real competitive PCR for high-throughput quantitative applications. Anal Biochem 2005, 339:23I-24I.

24. Campino S, Forton J, Raj S, Mohr A, Auburn S, Fry A, Mangano V, Vandiedonck C, Richardson A, Rockett K, Clark T, Kwiatkowski D: Validating discovered cis-acting regulatory genetic variants: application of an allele specific expression approach to HapMap populations. PLoS ONE 2008, 3(I 2):

25. Spielman RS, McGinnis RE, Ewens WJ: Transmission test for linkage disequilibrium: the insulin gene region and insulindependent diabetes mellitus (IDDM). Am J Hum Genet 1993, 52:506-516.

26. Cordell HJ: Properties of case/pseudocontrol analysis for genetic association studies: Effects of recombination, ascertainment, and multiple affected offspring. Genet Epidemiol 2004, 26: 186-205.

27. Teare MD, Heighway J, Santibanez Koref MF: An expectation-maximization algorithm for the analysis of allelic expression imbalance. Am J Hum Genet 2006, 79:539-543.

28. Morley M, Molony CM, Weber TM, Devlin JL, Ewens KG, Spielman RS, Cheung VG: Genetic analysis of genome-wide variation in human gene expression. Nature 2004, 430:743-747.

29. Goring HH, Curran JE, Johnson MP, Dyer TD, Charlesworth J, Cole SA, Jowett JB, Abraham LJ, Rainwater DL, Comuzzie AG, Mahaney MC, Almasy L, MacCluer JW, Kissebah AH, Collier GR, Moses EK, Blangero J: Discovery of expression QTLs using large-scale transcriptional profiling in human lymphocytes. Nat Genet 2007, 39:1208-1216.
Publish with Biomed Central and every scientist can read your work free of charge

"BioMed Central will be the most significant development for disseminating the results of biomedical research in our lifetime. "

Sir Paul Nurse, Cancer Research UK

Your research papers will be:

- available free of charge to the entire biomedical community

- peer reviewed and published immediately upon acceptance

- cited in PubMed and archived on PubMed Central

- yours - you keep the copyright

Submit your manuscript here:

http://www.biomedcentral.com/info/publishing_adv.asp
BioMedcentral 